\title{
Excitation and Inhibition in Epilepsy
}

\author{
Jerome Engel, Jr.
}

\begin{abstract}
The term epileptic seizures is used to describe a variety of paroxysmal signs and symptoms resulting from a large number of underlying pathological processes. Generalized tonicclonic convulsions, therefore, reflect entirely different basic neuronal mechanisms than those of typical absences. Animal research suggests that the former result from disturbances that involve disinhibition. whereas the abnormality giving rise to the latter requires intact, if not enhanced, inhibition in order to sustain hypersynchronous neuronal discharges. Investigations in human mesial temporal lobe epilepsy and chronic experimental animal models indicate that partial seizures can also reflect multiple underlying mechanisms, with some disinhibitory in type, while others appear to be hypersynchronous and associated with enhanced inhibition. Just as more than one epileptogenic disturbance can result in transition to ictus, it is likely that more than one mechanism can be engaged to terminate epileptic seizures, that these diverse processes could result in different postictal manifestations, and thitl they could conceivably contribute differently to the development of interictal behavioral disturbances. An appreciation for the fact that epilepsy is not merely an increase in excitation and/or a decrease in inhibition, but a variety of complicated neuronal interactions in different patients, or even at different times in the same patient or same seizure, is essential to the development of effective treatments to control epileptic seizures and prevent their consequences.
\end{abstract}

\begin{abstract}
RÉSUMÉ: Excitation et inhibition dans l'épilepsie. Le terme crise d'épilepsie est utilisé pour décrire une variété de signes et de symptômes paroxystiques résultant d'un grand nombre de processus pathologiques sous-jacents. lets convulsions toniques-cloniques généralisées reflètent donc des mécanismes neuronaux de base qui sont entièremént différents de ceux des absences typiques. La recherche chez l'animal suggère que les premières résultent de perturbations qui impliquent une désinhibition, alors que les secondes résultent d'une anomalie qui requière une inhibition intacte ou même accrue pour maintenir des décharges neuronales hypersynchrones. L'investigation de l'épilepsie mésiale du lobe temporal chez l'humain et chez des modèles animaux d'épilepsie expérimentale chronique indiquent que les crises partielles peuvent également refléter des mécanismes sous-jacents multiples. dont quelques uns sont de type désinhibition alors que d'autres semblent être hypersynchrones et associés à une inhibition accrue. Comme plus d'une perturbation épileptogène peut prédisposer à l'ictus, il est également possible que plus d'un mécanisme peut être mobilisé pour mettre fin à une crise d'épilepsie, que ces divers processus pourraient donner lieu à des manifestations postcritiques différentes et qu'ils pourraient vaaisemblablement contribuè différemment au développement de perturbations du comportement entre les crises. Il est essentiel de reconnaitre que l'épilepsie n'est pas seulement une augmentation de l'excitation et/ou une diminution de l'inhibition, mais une variété d'interactions neuronales complexes chez différents patients ou même à différents moments che\% le même patient ou pendant la même crise afin de développer des traitements efficaces pour contrôler les crises d'épilepsie ut en prévenir les conséquences.
\end{abstract}

Can. J. Neurol. Sci. 1996; 23: 167-174

Epileptic seizures are classically viewed as hyperexcitable phenomena, and the epileptic conditions that predispose to these ictal events are presumed to involve a chronic imbalance in neuronal excitatory and inhibitory influences. Modern clinical epileptology, however, recognizes that there are many types of epileptic seizures ${ }^{1}$ and many different forms of epilepsy and epileptic syndromes. ${ }^{2}$ Furthermore, research into fundamental mechanisms of epilepsy utilizing a variety of experimental models, as well as invasive studies of patients undergoing surgical treatment for epilepsy, have revealed that different types of epileptic seizures, and indeed different epileptic syndromes, result from different underlying disturbances at the cellular level. ${ }^{3}$ It is not the intention of this brief review to summarize the vast amount of recent data accumulated on excitation and inhibition in epilepsy, but rather to provide evidence supporting the contention that some partial seizures, as well as some generalized seizures, result, at least in part, from increased inhibitory influences, leading to hypersynchronization as the primary epileptogenic phenomenon.

From the Departments of Neurology and Neurobiology and the Brain Research Institute, UCLA School of Medicine, Los Angeles. RECEIVED NOVEMBER 21, 1995. ACCEPTED JANUAKY 25, 1996.

Presented in part as the Canadian Socicty of Clinical Neurophysiologists Guest Lecture, Victoria, B.C., June 22, 1995.

Reprint requests to: Jerome Engel, Jr., M.D., Ph.D., Reed Neurological Reseanch Center, 710 Westwood Plaza, Los Angeles, CA 90095-1769 USA 


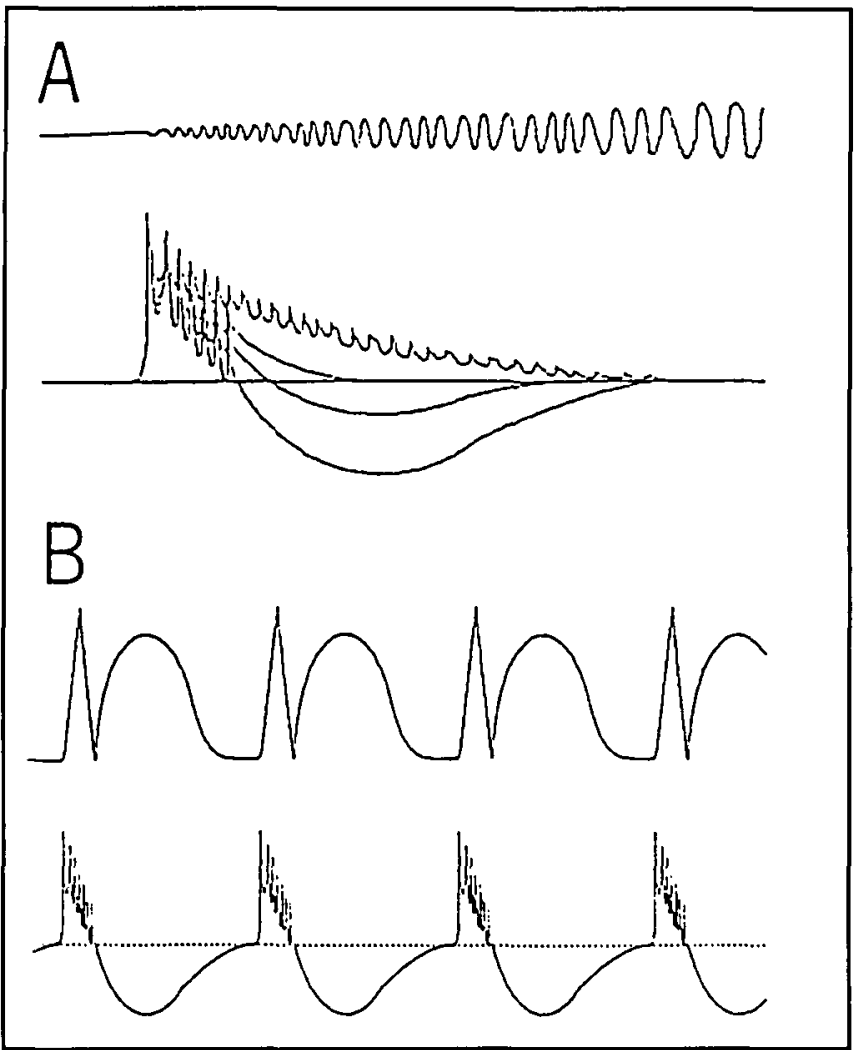

Figure 1: A. The neuronal mechanism of the ictal recruiting rhythm is illustrated schematically here. The lower trace represents an intracellular recording of a paroxysmal depolarization shift (PDS), demonstrating how the afterhyperpolarization gradually disappears to become an afterdepolarization, giving rise to continuous high frequency action potential discharge. The EEG in the upper trace increases in amplitude and slows in frequency as more and more neurons are recruited into this process and develop increasing synchrony. $B$. The neuronal mechanism of a hypersynchronous ictal discharge is schematically illustrated here. The lower trace shows an intracellular recording of recurrent PDSs. As with the interictal spike-and-wave discharge, the EEG spike, seen in the upper tracing, represents a summation of afterhyperpolarizations. In the ictal state, however, each hyperpolarization is followed immediately by another PDS, creating a repetitive hypersynchronous discharge such as the classical three-persecond spike-and-wave pattern of petit mal absences. A similar mechanism appears to underlie some partial ictal events as well. Reprinted from Ref. 3, with permission from Elsevier Science Ireland Ltd.

\section{Generalized Seizures}

The International Classification of Epileptic Seizures ${ }^{1}$ defines generalized seizures as those beginning in both hemispheres simultaneously and partial seizures as those beginning in a part of one hemisphere. Among the generalized seizures, there is no doubt that convulsive events (tonic clonic, tonic, and clonic seizures) utilize neuronal mechanisms that are distinctly different from those of typical, and probably also atypical, absence seizures (Figure 1). ${ }^{3,4}$ The ictal EEG of generalized convulsions usually begins with a buildup of low voltage fast activity, the so-called recruiting rhythm, which presumably corresponds to loss of the protective afterhyperpolarization and prolonged neuronal depolarization with rapid continuous action potential firing from the axon hillock. ${ }^{5}$ The ictal EEG of absence seizures consists of high amplitude repetitive spike-and-wave discharges identical to the interictal spike-and-wave transients seen in these disorders. Intracellular microelectrode investigations in animal models of absence seizures reveal only a moderate membrane depolarization underlying the spike, but a large chloride-sensitive hyperpolarization underlying the wave indicating that the wave represents synchronized GABA-mediated inhibitory events. ${ }^{6}$ The spike-and-wave discharges of typical absence seizures are now believed to be driven by pacemaker neurons in the thalamus which fire rhythmically when tonic inhibition mediated by $\mathrm{GABA}_{\mathrm{B}}$ receptors produces sufficient hyperpolarization to activate so-called low threshold $(\mathrm{T})$ calcium currents. ${ }^{7}$ Anti-petit mal drugs appear to exert their antiepileptic effects by blocking these $\mathrm{T}$ currents in the thalamus, ${ }^{8}$ while GABA agonists exacerbate absence-like seizures in the animal laboratory. ${ }^{4}$ Anti-petit mal drugs are not effective against convulsive seizures and in fact can make them worse, while anticonvulsant drugs are not effective against petit mal absences and can make these ictal events worse. ${ }^{9}$ Consequently, two distinctly different ictal onset patterns can be identified: 1) disinhibition, involving a loss in the afterhyperpolarization and an increase in excitatory influences; and 2) hypersynchrony involving enhanced inhibition and also perhaps enhanced excitation. Neither human nor animal research has yet revealed the fundamental mechanisms underlying other types of generalized ictal events, such as myoclonic seizures and atonic seizures, and it is likely that these are yet again distinct from those of both convulsive and absence seizures.

\section{Partial Seizures}

There is reason to believe that partial seizures may also involve more than one epileptogenic mechanism depending on the nature and location of the primary localized disturbance. Certain experimental neocortical epileptogenic perturbations induce a disinhibitory type transition to ictus, ${ }^{5}$ consistent with the recruiting rhythm seen at the onset of human partial seizures. Depth electrode recordings from human epileptic hippocampus, however, reveal both disinhibitory and hypersynchronous focal ictal onsets, the latter consistent with a mechanism more similar to that of absence than to convulsive seizures (Figures 2 and 3). ${ }^{10}$ In fact, hypersynchronous ictal onsets are much more common in hippocampus, while disinhibitory onsets may be more common in neocortex..$^{11,12}$ Whether this distinction reflects fundamental differences between the normal function and structure of mesial temporal limbic structures, including hippocampus, and those of neocortex, or whether the characteristic ictal onset patterns represent a unique pathophysiological process peculiar to the cell loss and neuronal reorganization that occurs with hippocampal sclerosis, remains to be determined. Nevertheless, invasive studies carried out in the course of surgical treatment for temporal lobe epilepsy have revealed disturbances that are not consistent with the concept of hyperexcitability, or disinhibition, as the sole cause of partial epilepsy. Rather, there is evidence for increased inhibition in human temporal lobe epilepsy. This inhibition may play an important protective role in maintaining the interictal state, but could also contribute to the spontaneous appearance of hypersynchronous ictal events and perhaps to the development of interictal behavioral disturbances. The remainder of this paper will examine some of the results of invasive investigations of 


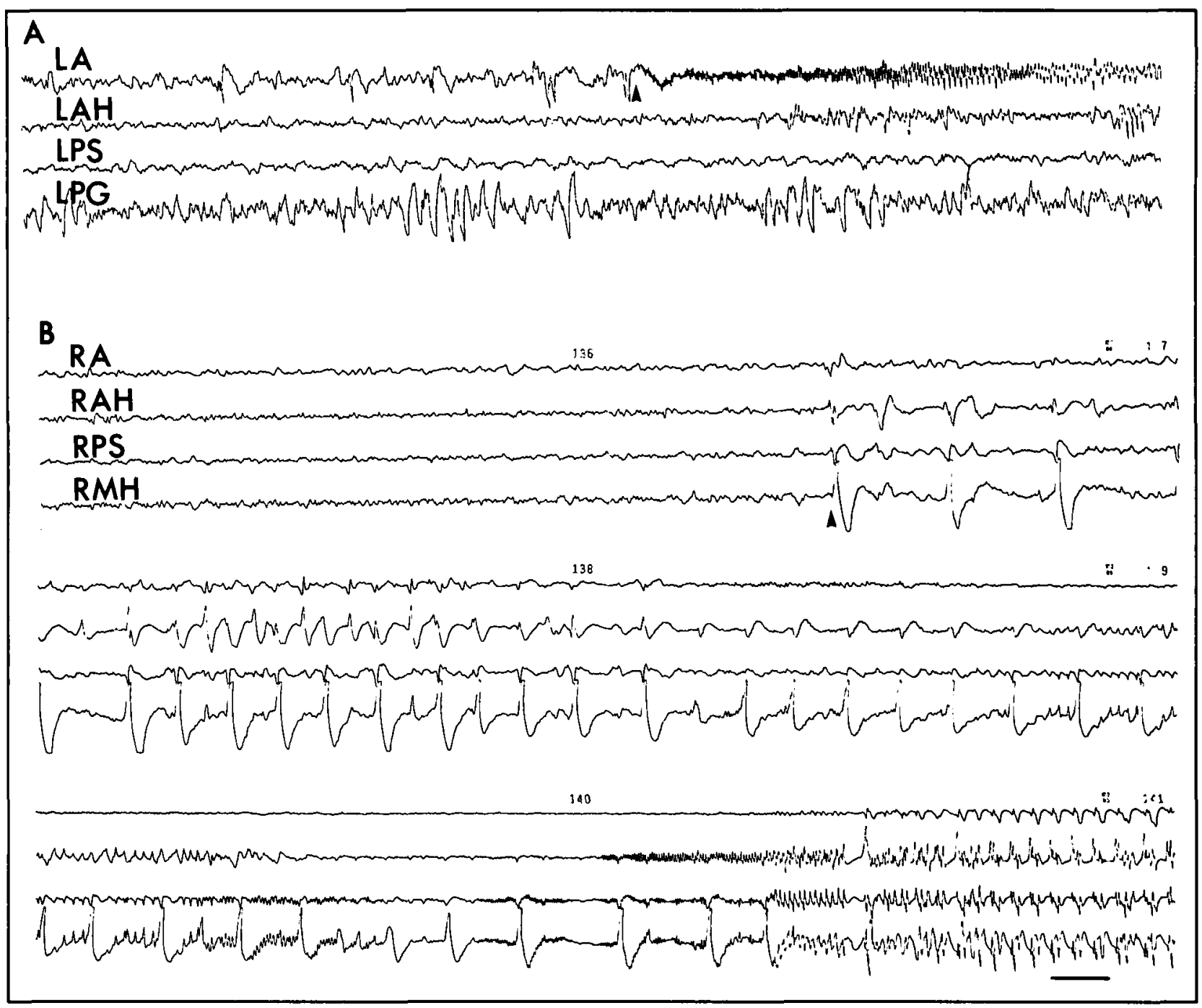

Figure 2: Segments of telemetry recordings from two patients showing SEEG activity at selected depth electrode bipolar tips during the onset of complex partial seizures. A. The classical depth electrode recorded ictal onset consists of a buildup of low voltage fast discharge, here beginning in a single channel (arrow). B. Three continuous segments show a more common ictal onset pattern, beginning with rhythmic high amplitude sharp and slow' transients (arrow), eventually giving way to a low voltage fast discharge, which then evolves into higher amplitude repetitive spikes or spikes-andwaves. L-left, R-right, A-amygdala, AH-anterior hippocampus, MH-mid hippocampus, PS-presubiculum, PG-posterior hippocampal gyrus. Calibration 1 second. From Ref. 10, with permission.

human temporal lobe epilepsy and relevant animal models revealing evidence that the epileptogenic process is different from that suggested by studies on experimental animal models of neocortical partial epilepsy.

\section{The Interictal State of Temporal Lobe Epilepsy}

Presurgical evaluation of patients with intractable seizures permits invasive electrophysiological studies to be performed during the course of routine diagnostic testing. In vivo microelectrode recordings of human epileptic hippocampus demonstrate that some neurons fire with burst discharges during the spike and stop firing during the wave of spontaneous interictal spike-and-wave EEG transients, suggesting that these events reflect the same paroxysmal depolarization shift and afterhyperpolarization membrane shifts underlying spike-and-wave transients seen in the experimental neocortical penicillin focus. ${ }^{13.14}$ In the human, however, only a small percentage of cells take part in these events, in contrast to the almost total participation of neurons in the penicillin focus. Because only a small number of cells are involved, it is difficult to demonstrate hypersynchrony in the epileptic human hippocampus, compared to the contralateral side, although hypersynchrony of inhibitory events appears to be more pronounced in the hippocampus where seizures originate. ${ }^{15}$ When synchronization between units is examined, those with strong inhibition are highly synchronized, while those with weak inhibition are not ${ }^{16}$ (Figure 4). This suggests that inhibitory events play an important role in producing synchronous epileptiform discharges in the human epileptic hippocampus, just as inhibition is important in the generation of synchronization in the normal brain, ${ }^{17}$ and in petit mal epilepsy?

Further electrophysiological evidence for enhanced inhibitory tone of the human epileptic hippocampus during the interictal state comes from stimulation studies of patients with implanted depth electrodes. Although paired pulse facilitation occurs when 


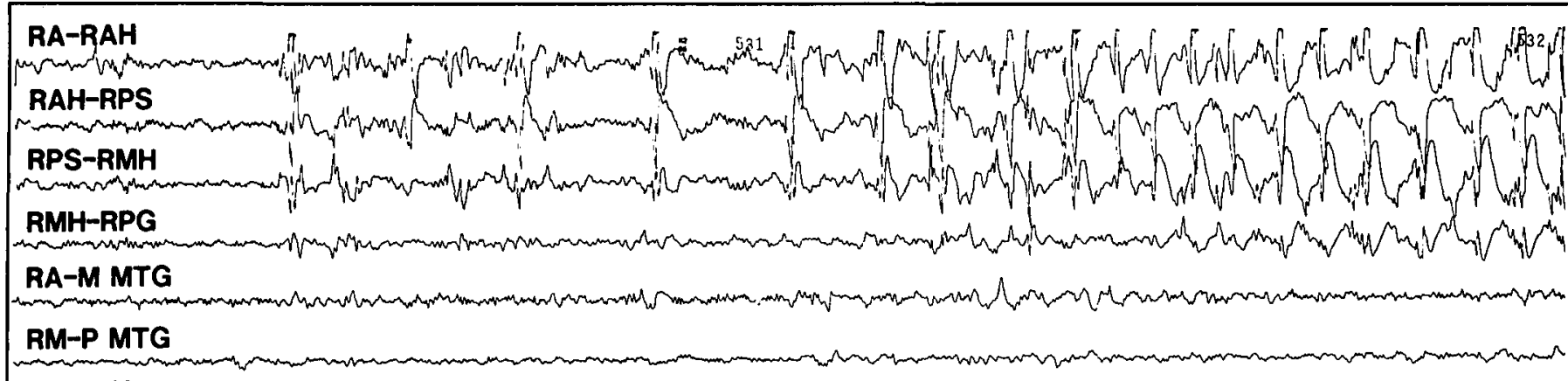

LA-LAH LAH-LPS

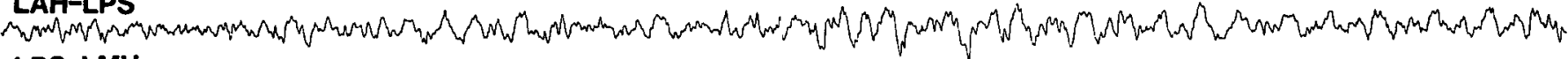
LPS-LMH

\section{LA-M MTG}

\section{LM-P MTG}

\section{T4-S2}

T-S2 4) S2-51

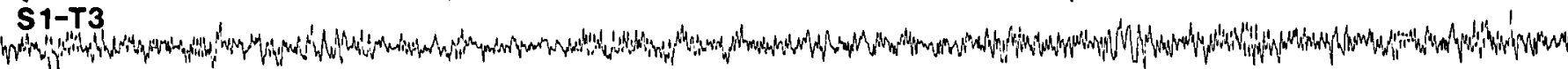

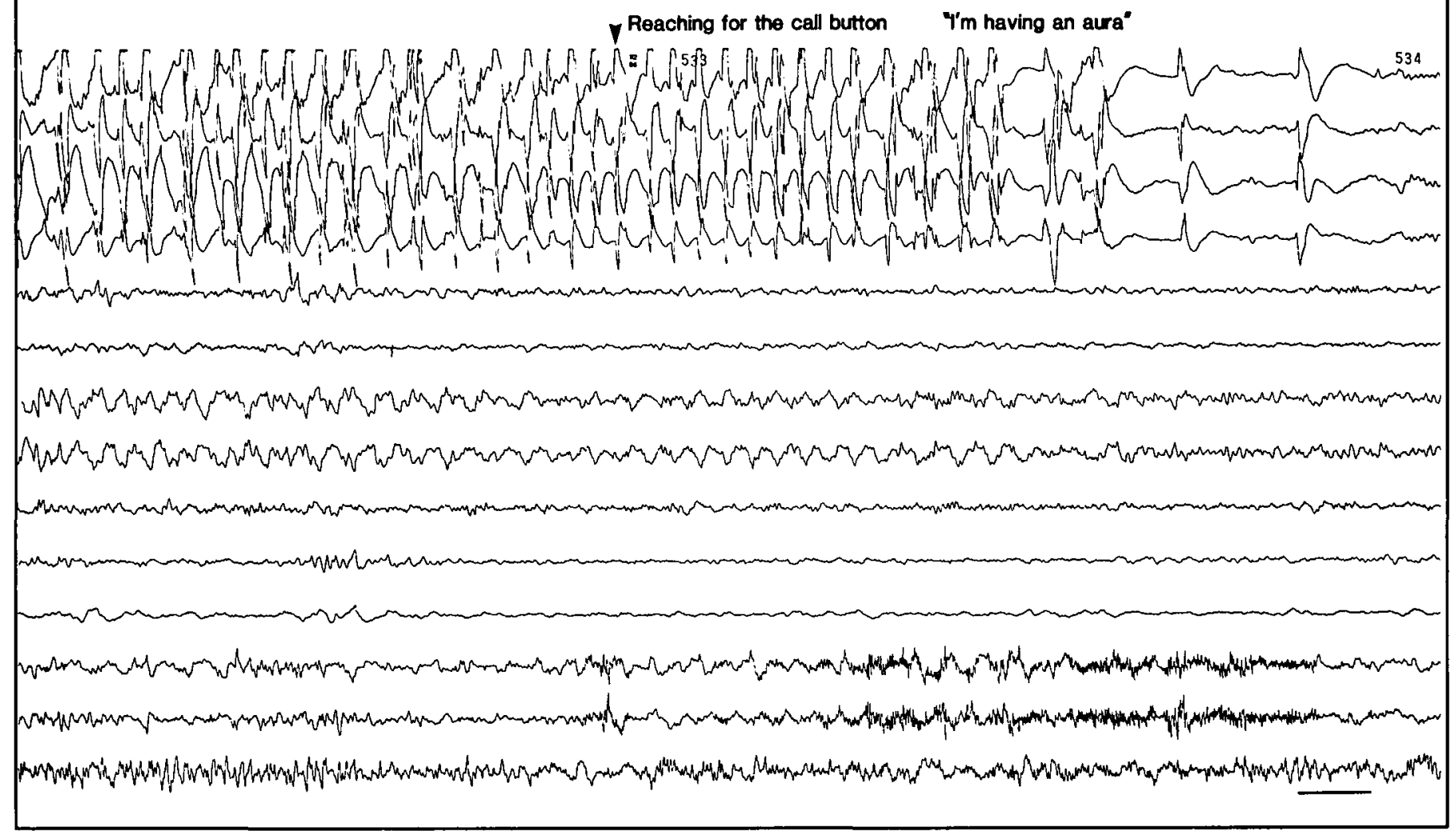

Figure 3: Forty continuous seconds of an EEG recorded from depth, sphenoidal and scalp electrodes during a simple partial seizure of the right temporal lohe. Ictal onset consists of an increase in interictal spike discharges, maximal at the right anterior hippocampal electrode (left portion of the upper pancl). After 8-9 seconds, these spikes become regular, eventually developing into a $3 \mathrm{~Hz}$ spike-and-wave pattern involving all derivations from the right mesial tenporal lobe. Note that no low voltage fast activity is seen, either initially, or at any part of the ictal episode. The patient reached for the call button at the arrow, at which point regular slow activity is also seen in the left anterior hippocampus and in the right sphenoidal electrode. The patiem then indicated an aura consisting of a sensation of fear in her stomach. Depth electrode locations indicated as in Figure 2. Superficial contacts from anterior $(A)$, mid $(M)$. and posterior $(P)$ depth electrodes recorded from cortex of middle temporal gyrus (MTG). Calibration I second. From Ref. 10, with permission. 


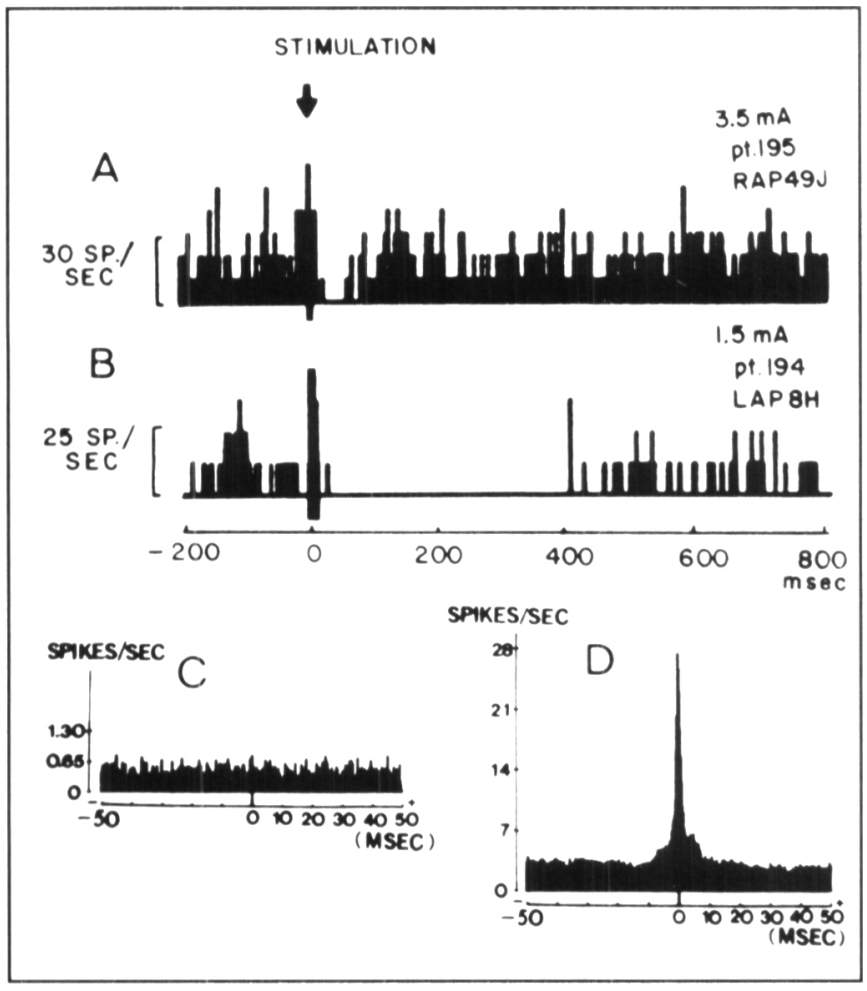

Figure 4: Unit histograms from human epileptic hippocampus show weak firing suppression $(A)$ in neurons that were not firing synchronously as determined by cross-correlation histograms (C), and strong firing suppression $(B)$ in neurons that were firing synchronously $(D)$. This provides indirect evidence for recurrent inhibitory circuits as a mechanism of hypersynchronization. From Ref. 16, with permission.

the stimulating and recording electrodes are both within the hippocampus, paired pulse suppression is seen in the epileptic hippocampus when the stimulation site is the perforant path. ${ }^{18}$ These observations have also been reproduced in experimental animal models of temporal lobe epilepsy, ${ }^{19}$ and indicate a preponderance of inhibitory neuronal interactions at the level of the dentate gyrus, but a preponderance of excitatory interactions within the hippocampal subfields. The observation that afterdischarge thresholds are elevated in the human epileptogenic hippocampus when compared to the contralateral side ${ }^{20}$ may also reflect enhanced inhibition in this area which might differentiate it from neocortical epileptogenic regions where afterdischarge thresholds are traditionally believed to be reduced. ${ }^{21}$

Another feature that appears to differentiate mechanisms of mesial temporal limbic seizures from those of neocortical seizures is demonstrated by interictal ${ }^{18} \mathrm{~F}$-fluorodeoxyglucose positron emission tomography (FDG-PET). A high percentage of patients with mesial temporal epileptogenic lesions, particularly hippocampal sclerosis, demonstrate widespread temporal lobe hypometabolism with FDG-PET that may also involve the ipsilateral thalamus, basal ganglia, and neocortex of adjacent lobes. ${ }^{22}$ This indicates a persistent transsynaptic functional deficit that extends well beyond any structural abnormality observed on MRI or under the microscope. Conversely, patients with neocortical onset partial seizures rarely demonstrate hypometabolism beyond the boundaries of an identified structural lesion on interictal FDG-PET, ${ }^{23}$ indicating that these transsynaptic functional changes are much weaker, or perhaps even nonexistent. It is likely that mesial temporal limbic epilepsy requires participation of a large network of structurally and functionally abnormal neurons for manifestation of complex partial seizures, while neocortical seizures may result from epileptogenic activity within a much more discrete group of neuronal elements. This view is supported by the fact that patients with hippocampal sclerosis frequently experience residual auras following radical anterior temporal lobectomy, which clearly removes all structural abnormalities. ${ }^{24}$

Although the large hypometabolic zone in human temporal lobe epilepsy was initially interpreted to represent the inhibitory surround seen in association with the experimental neocortical penicllin focus, ${ }^{25}$ it was subsequently demonstrated that GABAmediated inhibition requires enhanced glucose melabolism. ${ }^{26}$ Some other inhibitory process must, therefore, underlic the widespread reduced neuronal activity seen interictally in this disorder. Endogenous opioid peptide-mediated influences have been implicated from work on experimental animal models. ${ }^{27-29}$

Some information on interictal neurotransmitter function within the human epileptic temporal lobe has been obtained from PET studies using specific ligands. Binding of carfentanil, a $\mu$ opiate receptor ligand, is enhanced in the temporal neocortex on the side of onset of temporal lobe seizures, ${ }^{30}$ which is consistent with an enduring enhancement of opiate-mediated inhibition at a distance from the site of ictal onset. ${ }^{31}$ Binding of flumazenil, a benzodiazepine receptor ligand, is decreased in mesial temporal structures on the side of seizure onset, 32,33 which could mean either decreased sensitivity of the postsynaptic membrane to GABA-mediated inhibition or a down regulation of receptors in response to enhanced release of GABA within the epileptogenic region. In vivo microdialysis investigations are also now being performed at some centers in association with depth electrode recordings, and sampling of extracellular fluid from the epileptic human hippocampus does in fact reveal increased postassium-stimulated release of GABA during the interictal state, although glutamate-induced calciumdependent release of GABA is decreased..$^{3-4}$

Patients with intractable temporal lobe seizures who undergo surgical treatment provide mesial temporal tissue for in vitro investigations. Microelectrode studies of slices taken from human epileptic hippocampus have revealed the appearance of NMDA-mediated depolarization events, ${ }^{35}$ perhaps equivalent to those described in kindling, ${ }^{36}$ suggesting abnormally increased influence of the excitatory amino acid transmitters. Sprouting of dentate granule cell mossy fibers is a characteristic finding in human hippocampal sclerosis and suggests that cell loss results in synaptic reorganization that includes powerful monosynaptic excitatory feedback. ${ }^{37-39}$ This does not appear to be an absolute criterion for development of hippocampal epileptogenicity, however, since kindling persists in immature rats ${ }^{40}$ which do not demonstrate sprouting. ${ }^{41}$ Another characteristic feature of human hippocampal sclerosis is selective loss of somatostatin containing hilar neurons, ${ }^{42}$ which are inhibitory neurons that colocalize GABA. On the other hand, repeated studies have demonstrated relative sparing of GAD-containing inhibitory interneuron $\mathrm{s}^{43}$ and abundant inhibitory terminals on surviving principal neuron, ${ }^{44}$ providing morphological evidence for increased inhibition, perhaps involving sprouting of inhibitory terminals. Although inhibitory interneurons may survive, therc 
is evidence that their activation may be reduced, resulting in an overall decrease in inhibitory effect, the so-called "dormant basket cell hypothesis". ${ }^{45.46}$ Consequently, cell loss may result in synaptic reorganization that involves both excitatory and inhibitory axons in a manner that does not simply enhance excitation and reduce inhibition, but rather creates changes in the pattern of neuronal integration that predisposes to hypersynchronization in specific areas of hippocampus.

\section{Ictal Events of Temporal Lobe Epilepsy}

The high amplitude repetitive hypersynchronous discharges characteristic of ictal onset recorded from human epileptic hippocampus generally correlate with the occurrence of an aura or may be unassociated with any clinical signs or symptoms. This EEG pattern can cease spontaneously or eventually be replaced by a disinhibitory type recruiting rhythm at which point propagation to the contralateral hemisphere is seen and consciousness becomes impaired with evolution to a complex partial seizure. It is unclear at this time whether this transition involves a change in neuronal interactions within the hippocampus itself or propagation to adjacent neocortical structures, which may be predisposed to respond with a disinhibitory type ictal pattern. Whether the recruiting rhythm is generated within the hippocampus or within adjacent neocortex, it does appear that it is more likely than the hypersynchronous ictal event to propagate to distant structures, particularly the contralateral hemisphere. Because hypersynchronous ictal onsets are more commonly observed in patients with hippocampal sclerosis, this may reflect the peculiar cell loss and synaptic reorganization of this lesion, rather than some inherent difference between hippocampus and cortex. On the other hand, there is little or no functional connection across the human hippocampal commissure, ${ }^{47}$ suggesting that the propensity for the recruiting rhythm to propagate contralaterally can be attributed to its generation in neocortex, rather than the specific pathophysiological properties of a disinhibitory ictal event. Animal studies are underway, utilizing the intrahippocampal kainic acid model of hippocampal sclerosis in rats ${ }^{48}$ to identify the specific anatomical substrates and neuronal events underlying hypersynchronous and disinhibitory ictal discharges in spontaneous partial seizures of mesial temporal origin.

In vivo microdialysis studies of human temporal lobe epilepsy have documented an increase in ictal release of GABA, as well as of excitatory amino acids, suggesting that discharging inhibitory interneurons play an important role in mediating at least some aspect of temporal lobe seizures. ${ }^{49.50}$ More work is necessary before neurotransmitter release can be correlated with specific electrographic patterns, and microdialysis experiments in the rat intrahippocampal kainate model are also being used to supplement these studies in patients. ${ }^{50}$ Microdialysis in kindled rats has demonstrated that release of endogenous opioids during seizures may increase or decrease depending on the structure observed. ${ }^{51}$ Therefore, it is quite likely that regional differences in GABA and excitatory amino acid release will also be seen that will greatly complicate analysis of interactions between various limbic, cortical, and subcortical structures that underlie the transition from interictal to ictal state, as well as the characteristic ictal evolution of temporal lobe simple to complex partial seizures. An imbalance in excitatory and inhibitory influences will undoubtedly be demonstrated, but it is highly unlikely that this will uniformly consist of increased excitation and decreased inhibition. Rather, some or many structures may also demonstrate increased inhibition, leading to hypersynchronization and the interplay between disinhibited and hypersynchronous neurons within a given structure, and between disinhibited and hypersynchronous structures ipsilateral and contralateral to the site of seizure onset over time, will determine when a spontaneous seizure will occur, while changes in the pattern of neuronal and systems interactions during the course of the ictal event will determine what type of seizure ensues.

\section{The Postictal State of Temporal Lobe Epilepsy}

Epileptic seizures are self-limiting and natural mechanisms are engaged to actively terminate ictal events. Much less is known, however, about why seizures stop than about how they are generated. Presumably, just as there are multiple different neuronal mechanisms for seizure generation, there must also be multiple neuronal mechanisms for seizure cessation. For instance, the recruiting EEG rhythm at the onset of a generalized convulsion eventually gives way to a period of intermittent EEG suppression, associated with the clonic phase of the tonicclonic seizure, which appears to reflect a phasing in of an active inhibitory process that ultimately terminates the ictal event. Although depolarization block may contribute to this phenomenon, inhibitory systems involving GABA, adenosine and opioid peptides are also known to be involved. ${ }^{52.53}$ On the other hand, the hypersynchronous rhythmic discharges of typical absence seizures may end as a result of some desynchronizing process that does not necessarily involve active tonic inhibition. In fact, hypersynchronous ictal events can be produced in rats by intracerebroventricular injection of the same endogenous opioids that are released at the termination of generalized convulsions. ${ }^{54}$ The postictal depression that inevitably follows a generalized convulsion most likely reflects persistence of those inhibitory mechanisms that terminated the ictal event. The fact that typical petit mal absences are not followed by postictal disturbances is further evidence that they end as a result of an entirely different process.

Some partial seizures also appear to be terminated by active inhibitory mechanisms which can produce postictal focal deficits such as Todd's paralysis, ${ }^{55}$ or in some cases prolonged but reversible disturbances lasting many months. ${ }^{56}$ In temporal lobe epilepsy, complex partial seizures which involve bilateral limbic structures and are associated with loss of consciousness are followed by a period of behavioral and EEG abnormalities which also could reflect effects of the active inhibitory mechanisms that terminate the ictal event. Numerous studies indicate that opioid peptides play a role in mediating these postictal behaviors. ${ }^{28.57}$ FDG-PET scans obtained during complex partial seizures show diffuse hypometabolism, presumably reflecting the contribution of postictal disturbances to the final averaged image, suggesting that this process is generalized; simple partial seizures confined to one mesial temporal area, however, do not show this phenomenon. ${ }^{56}$ No studies have been carried out to examine mechanisms of termination of hypersynchronous events in epileptic hippocampus, either in patients or experimental animal models; however, the fact that these often produce no signs or symptoms ${ }^{58}$ might suggest the absence of an active inhibitory mechanism of ictal termination.

Interictal behavioral disturbances consisting of affective disorders, such as depression, personality traits and even frank 
psychosis occur in patients with epilepsy and, although a controversial subject, have been reported by some to be most common in patients with temporal lobe epilepsy. ${ }^{59}$ Perhaps postictal disturbances peculiar to the limbic system persist in some patients to disrupt normal interictal behavior, or perhaps those homeostatic natural protective mechanisms that develop in order to maintain the interictal state impair normal neuronal function. Therefore, in addition to those alterations in excitatory and inhibitory influences that are responsible for epileptogenesis, investigations into other aspects of the chronically altered neuronal integration that exists in human temporal lobe epilepsy could provide insights into means to treat or prevent interictal behavioral disturbances that account for significant disability in this disorder.

\section{ACKNOWLEDGEMENTS}

Original research reported by the author was supported in part by Grants NS-02808, NS-15654, NS-33310, and GM-24839, from the National Institutes of Health, and Contract DE-AC03-76-SF000I 2 from the Department of Energy.

\section{REFERENCES}

1. Commission on Classification and Terminology of the International League Against Epilepsy. Proposal for revised clinical and electroencephalographic classification of epileptic seizures. Epilepsia 1981; 22: 489-501.

2. Commission on Classification and Terminology of the International League Against Epilepsy. Proposal for revised classification of epilepsies and epileptic syndromes. Epilepsia 1989; 30: 389-399.

3. Engel J Jr. Functional explorations of the human epileptic brain and their therapeutic implications. Electroencephalogr Clin Neurophysiol 1990; 76: 296-316.

4. Gloor P, Fariello RG. Generalized epilepsy: some of its cellular mechanisms differ from those of focal epilepsy. Trends Neurosci 1988; II: 63-68.

5. Matsumoto H, Ajmone-Marsan C. Cortical cellular phenomena in experimental epilepsy: ictal manifestations. Exp Neurol 1964; 9: 305-326.

6. Giaretta D, Avoli M, Gloor P. Intracellular recordings in pericruciate neurons during spike and wave discharges of feline generalized penicillin epilepsy. Brain Res 1987; 405: 68-79.

7. Avanzini G, Vergenes M, Spreafico R, Marescaux C. Calciumdependent regulation of genetically determined spike and waves by the reticular thalamic nucleus of rats. Epilepsia 1993; 34: 1-7.

8. Coulter DA, Huguenard JR, Prince DA. Specific petit mal anticonvulsants reduce calcium currents in thalamic neurons. Neurosci Lett 1989; 98: 74-78.

9. Levy RH, Mattson RH, Meldrum BS, eds. Antiepileptic Drugs, 4th edition. New York: Raven Press, 1995.

10. Engel J Jr. Brain metabolism and pathophysiology of human epilepsy. In: Dichter M, ed. Mechanisms of Epileptogenesis: Transition to Seizure. New York: Plenum Press, 1988; I-15.

11. Townsend JB, Engel J Jr. Clinicopathological correlations of low voltage fast and high amplitude spike and wave mesial temporal stereoencephalographic ictal onsets. Epilepsia 1991; 32 (Suppl. 3): 21.

12. King D, Spencer $S$. Invasive electroencephalography in mesial temporal lobe epilepsy. J Clin Neurophysiol 1995; 12: 32-45.

13. Babb TL, Crandall PH. Epileptogenesis of human limbic neurons in psychomotor epileptics. Electroencephalogr Clin Neurophysiol 1976; 40: 225-243.

14. Matsumoto $\mathrm{H}$, Ajmone-Marsan $\mathrm{C}$. Cortical cellular phenomena in experimental epilepsy: interictal manifestations. Exp Neurol 1964; 9: 286-304.

15. Colder BW, Wilson CL, Frysinger RC, et al. Neuronal synchrony in relation to burst discharge in epileptic human temporal lobes. $J$ Neurophysiol (in press).
16. Isokawa-Akesson M, Wilson CL, Babb TL. Prolonged inhibition in synchronously firing human hippocampal neurons. Epilepsy Res 1989; 3: 236-247.

17. Andersen $P$, Sears TA. The role of inhibition in the phasing of spontaneous thalamo-cortical discharge. J Physiol 1964; 173 : 459-480.

18. Wilson CL, Engel J Jr. Electrical stimulation of the human epileptic limbic cortex. In: Devinsky O, Beric A, Dogali M, eds. Electrical and Magnetic Stimulation of the Brain and Spinal Cord. New York: Raven Press, 1993; 103-113.

19. Kamphuis W, Gorter JA, Wytse JW, Lopes da Silva FH, Hippocampal kindling leads to different changes in paired-pulse depression of local evoked field potentials in CAI area and in fascia dentata. Neurosci Lett 1992; 141: 101-105.

20. Cherlow DG, Dymond AM, Crandall PH, Walter RD, Serafetinides EA. Evoked response and after-discharge thresholds to electrical stimulation in temporal lobe epileptics. Arch Neurol 1977; 34: 527-531.

21. Penfield W, Jasper H. Epilepsy and the functional anatomy of the human brain. Boston: Little, Brown \& Co., 1954.

22. Henry TR, Mazziotta JC, Engel J Jr. Interictal metabolic anatomy of limbic temporal lobe epilepsy. Arch Neurol 1993; 50: 582589.

23. Henry TR, Sutherling WW, Engel J Jr, et al. Interictal cerebral metabolism in partial epilepsies of neocortical origin. Epilepsy Res 1991; 10: 174-182.

24. Engel J Jr, Van Ness P, Rasmussen TB, Ojemann LM. Outcome with respect to epileptic seizures. In: Engel J Jr, ed. Surgical Treatment of the Epilepsies, 2nd edition. New York: Raven Press, 1993; 609-621.

25. Prince DA, Wilder BJ. Control mechanisms in cortical epileptogenic foci: "surround" inhibition. Arch Neurol 1967; 16: 194202.

26. Ackermann RF, Finch DM, Babb TL, Engel J Jr. Increased glucose metabolism during long-duration recurrent inhibition of hippocampal pyramidal cells. J Neurosci 1984; 4: 251-264.

27. Chugani HT, Ackermann RF, Chugani DC, Engel J Jr. Opioidinduced epileptogenic phenomena: anatomical, behavioral, and electroencephalographic features. Ann Neurol 1984; 15: 361368.

28. Caldecott-Hazard S, Engel J Jr. Limbic postictal events: anatomical substrates and opioid receptor involvement. Prog Neuropsychopharmacol Biol Psychiat 1987; 11: 389-418.

29. Rocha L, Ackermann RF, Engel J Jr. Effects of chronic morphine pretreatment on amygdaloid kindling development, postictal seizure suppression and benzodiazepine receptor binding in rats. Epilepsy Res (in press).

30. Frost JJ, Mayberg HS, Fisher RS, et al. Mu-opiate receptors measured by positron emission tomography are increased in temporal lobe epilepsy. Ann Neurol 1988; 23: 231-237.

31. Hitzemann RJ, Hitzemann BA, Blatt S, et al. Repeated electroconvulsive shock: effect on sodium dependency and regional distribution of opioid-binding sites. Mol Pharmacol 1987; 31: 562-566.

32. Savic I, Persson A, Roland P, et al. In-vivo demonstration of reduced benzodiazepine receptor binding in human epileptic foci. Lancet 1988; 8616: 863-866.

33. Henry TR, Frey KA, Sackellares JC, et al. In vivo cerebral metabolism and central benzodiazepine receptor binding in temporal lobe epilepsy. Neurology 1993; 43: 1998-2006.

34. During MJ, Ryder KM, Spencer DD. Hippocampal GABA transporter function in temporal-lobe epilepsy. Nature 1995; 376 : 174-177.

35. Isokawa $M$, Levesque MF. Increased NMDA responses and dendritic degeneration in human epileptic hippocampal neurons in slices. Neurosci Lett 1991; 132: 212-216.

36. Mody I, Stanton PK, Heinemann U. Activation of N-methyl-Daspartate receptors parallels changes in cellular and synaptic properties of dentate granule cells after kindling. J Neurophysiol 1988; 59: 1033.

37. Babb TL, Kupfer WR, Pretorius JK, Crandall PH, Levesque MF. Synaptic reorganization by mossy fibers in human epileptic fascia dentata. Neuroscience 1991; 42: 351-363. 
38. Houser CR, Miyashiro JE, Swartz BE, et al. Altered patterns of dynorphin immunoreactivity suggest mossy fiber reorganization in human hippocampal epilepsy. J Neurosci 1990; 10: 267-282.

39. Sutula T, Cascino G, Cavazos J, Parada I, Ramirez L. Mossy fiber synaptic reorganization in the epileptic human temporal lobe. Ann Neurol 1989; 26: 321-330.

40. Moshé SL, Albala BJ. Kindling in developing rats, persistence of seizures into adulthood. Dev Brain Res 1992; 4: 67-71.

41. Sperber EF, Stanton PK, Haas K, Ackermann RF, Moshé SL. Developmental differences in the neurobiology of epileptic brain damage. Epilepsy Res 1992; (Suppl. 9): 67-81.

42. deLanerolle NC, Brines ML, Kim JH, et al. Neurochemical remodeling of the hippocampus in human temporal lobe epilepsy. Epilepsy Res 1992; (Suppl. 9): 205-220.

43. Babb TL, Pretorius JK, Kupfer WR, Crandall PH. Glutaniate decarboxylase-immunoreactive neurons are preserved in human epileptic hippocampus. J Neurosci 1989; 9: 2562-2574.

44. Davenport CJ, Brown WJ, Babb TL. Sprouting of GABA-ergic and mossy fiber axons in dentate gyrus following intrahippocampal kainate in the rat. Exp Neurol 1990; 109: 180-190.

45. Sloviter RS. Permanently altered hippocampal structure, excitability and inhibition after experimental status epilepticus in the rat: the "dormant basket cell" hypothesis and its possible relevance to temporal lobe epilepsy. Hippocampus 1991; 1: 4I-66.

46. Berkenstein JW, Lothman EW. Dormancy of inhibitory interneurons in a model of temporal lobe epilepsy. Science 1993; 259: 97-100.

47. Wilson CL, Isokawa-Akesson $\mathrm{M}$, Babb TL, et al. A comparative view of local and interhemispheric limbic pathways in humans: an evoked potential analysis. $I n$ : Engel $\mathbf{J} \mathrm{Jr}$, Ojemann GA, Lüders HO, Williamson PD, eds. Fundamental Mechanisms of Human Brain Function. New York: Raven Press, 1987; 27-38.

48. Mathern GW, Cifuentes F, Leite JP, Pretorius JK, Babb TL. Hippocampal EEG excitability and chronic spontaneous seizures are associated with aberrant synaptic reorganization in the rat kainate model. Electroencephalogr Clin Neurophysiol 1993; 87: 326-339.
49. During MJ, Spencer DD. Extracellular hippocampal glutamate and spontaneous seizure in the conscious human brain. Lancet 1993; 341: 1607-1610.

50. Wilson C, Maidment NT, Shomer MH, et al. Comparison of seizure related amino acid release in human epileptic hippocampus versus a chronic, kainate rat model of hippocampal epilepsy. Epilepsy Res (in press).

51. Rocha LL, Maidment NT, Evans CJ, Ackermann RF, Engel J Jr. Opioid peptide release and mu receptor binding during amygdala kindling in rats: regional discordances. Epilepsy Res (in press).

52. Caldecott-Hazard S, Shavit Y, Ackermann RF, et al. Behavioral and electrographic effects of opioids on kindled seizures in rats. Brain Res 1982; 251: 327-333.

53. Dragunov M, Goddard GV, Laverty R. Is adenosine an endogenous anticonvulsant? Epilepsia 1985; 26: 480-487.

54. Snead OC, Bearden LJ. The epileptogenic spectrum of opiate agonists. Neuropharmacology 1982; $21: 1137-1144$.

55. Efron R. Post-epileptic paralysis: theoretical critique and report of a case. Brain 1961; 84: 381-394.

56. Engel J Jr, Kuhl DE, Phelps ME, Rausch R, Nuwer M. Local cerebral metabolism during partial seizures. Neurology 1983; 33: 400-413.

57. Frenk H, Engel J Jr, Ackermann RF, Shavit Y, Liebeskind JC. Endogenous opioids may mediate post-ictal behavioral depression in amygdaloid-kindled rats. Brain Res 1979; 167: 435440.

58. Sperling MR, O'Connor MJ. Auras and subclinical seizures: characteristics and prognostic significance. Ann Neurol 1990; 28: 320-328.

59. Engel J Jr, Bandler R, Griffith NC, Caldecott-Hazard S. Neurobiological evidence for epilepsy-induced interictal disturbances. In: Smith D, Treiman D, Trimble M, eds. Advances in Neurology, New York: Raven Press, 1991; 55: 97-111. 